\title{
El Español en el Marco Común Europeo
}

\author{
The spanish language in the Common European Framework
}

\author{
Manuel Peñalver Castillo
}

Departamento de Filología, Facultad de Humanidades, Universidad de Almería.
Correo electrónico: mpenalver@hotmail.com

\begin{abstract}
El texto debe ser el fin y el referente de esta aplicación metodológica como resultado de la suma de todas las competencias (o saberes), entre las que no pueden quedar al margen la competencia psicolingüística y la competencia sociolingüística. Una competencia comunicativa, basada en una sólida competencia lingüística, en la que se integren de forma equilibrada las competencias fónica, gramatical, semántica y léxica, por un lado, y, por otro, la competencia pragmática, la sociolingüística, la psicolingüística, la paralingüística y la discursiva, favorecerá, en todas sus dimensiones, el proceso de enseñanza y aprendizaje, encaminado a la producción de textos escritos y orales en la diversidad de su manifestación.
\end{abstract}

Palabras clave: competencia comunicativa, lingüística, pragmática, sociolingüística, psicolingüística.

The text has to be the end and the referent of this methodological application like result of the sum of all the competitions (or knowledges), between which can not remain to the margin the competition psicolinguistic and the sociolinguistic competition. A communicative competition, based in a solid linguistic competition, in which they integrate of form balanced the phonic competitions, grammatical, semantic and lexical, on the one hand, and, by another, the pragmatic competition, the sociolinguistics, the psicolinguistic, the paralinguistic and the discursiva, will favour, in all his dimensions, the process of education and learning, directed to the production of written and oral texts in the diversity of his demonstration.

Key words: communicative competencies, linguistic, pragmatic, sociolinguistics, psycolinguistics.

\section{INTRODUCCIÓN}

La falta de una auténtica preocupación pedagógica por el español como lengua materna ha sido, sin duda, un aspecto ciertamente negativo. En España, el carácter casi exclusivamente teórico de los programas, de los exámenes y la duradera influencia de la gramática tradicional han sido causas que pueden explicar esta falta de interés por la renovación pedagógica. La enseñanza de una asignatura tan esencial en la educación 
como es la de Lengua Española necesita, ineludiblemente, la presencia en los planes de estudios universitarios de asignaturas de didáctica, que sirvan para la consecución de una adecuada formación del profesorado de la misma (Peñalver 1991).

La escasez de estudios serios y profundos sobre los fundamentos didácticos de nuestra lengua es manifiesta. Estos estudios deben tratar con equilibrio las relaciones entre lo teórico y lo práctico, entre la lingüística y la didáctica, entre la propia lingüística y la lingüística aplicada. Al mismo tiempo, deben aplicarse las aportaciones de la pragmática, de la sociolingüística y de la psicolingüística a la enseñanza de la lengua. Conseguir la plena coordinación entre las investigaciones lingüísticas y pedagógicas debe constituir una prioridad en los objetivos y en los fines para que los resultados mejoren.

Para modernizar y actualizar la didáctica de la asignatura de Lengua Española en todos sus niveles es absolutamente necesaria la relación y la coordinación entre docentes y lingüistas, entre lingüística y pedagogía. Pero, como hemos señalado, la escasez de buenas publicaciones sobre didáctica de la Lengua Española es bien notoria. Sobre esta pobreza bibliográfica A. Medina manifestaba (1988: 21): "De la anteguerra, resaltar la voz autorizada de Castro (1922), los libros de Torner (1936), de Tirado (1937) y la obra de Carrasco (1935), que es sin disputa la más seria meditación teórico-práctica de base psicológica, que de la Didáctica de la Lengua se haya publicado en España. De la guerra a acá, opúsculos, monografías, libros, misceláneas, parcelaciones sobre cada una de las esferas de amplio espectro que conforman la enseñanza de la lengua (lectura, escritura, gramática...). Pero echamos en falta la visión conjunta de un tratado de la enseñanza de la lengua en la educación elemental, conexionados didacta y lingüista, y no fragmentando en secciones que se ignoren".

La enseñanza de la asignatura de Lengua Española necesita, por tanto, una seria planificación metodológica de forma que sintetice, equilibradamente, los aspectos pedagógicos y científicos y evite los errores anteriores y algunos actuales. Sólo de este modo se podrá evitar que sigan apareciendo afirmaciones tan pesimistas como aquellas de J. Polo (1972: 96): "Se espera que el alumno que ingresa en la Universidad, en una Facultad de Letras al menos, posea cierta capacidad crítica, alguna orientación en cuestiones de gramática normativa (teoría) y, por supuesto, la mecánica de la lengua: léxico suficiente, buena construcción, ausencia de errores ortográficos".

Por tanto, esta renovación metodológica debe constituir una auténtica realidad y un camino de esperanza para conseguir que los resultados pedagógicos de una asignatura tan relevante tengan un alto nivel tanto científico como didáctico, porque no olvidemos nunca que, como afirma M. ${ }^{a}$ Dolores Poch Olive (1983: 220), "el profesor de lengua materna debe procurar que el alumno llegue al final del Bachillerato conociendo profundamente los recursos expresivos del español, lo que presupone lograr el desarrollo de sus capacidades intelectuales" o, como también señalaba L. González Nieto (1981:181), "la de crear ciudadanos que sean capaces de leer, en todos los sentidos que una persona culta y crítica da a esta palabra, y de expresar exacta y rigurosamente lo que quieren. Es el tipo de ciudadanos que exige una sociedad democrática".

Hay que decir de manera muy clara que los resultados de la asignatura de Lengua Española en los niveles de la Enseñanza Secundaria (ESO) y Bachillerato no son, precisamente, satisfactorios por muy diversos motivos y razones. En relación con 
esta consideración, constituye un hecho claro que la expresión escrita y oral presenta muchas deficiencias: desde la ortografía (en el caso concreto de la lengua escrita) hasta la gramática y el léxico, en sus aplicaciones y usos en los distintos tipos de textos. Si atendemos a esta realidad, hay que recuperar, entonces, los dictados, las redacciones y otras actividades que sirvan para que los alumnos mejoren su competencia comunicativa $\mathrm{y}$, en consecuencia, la expresión tanto en el plano del español escrito como en el plano del español hablado. De poco han servido, pues, las innovaciones pedagógicas, las reformas y los cambios de planes de estudios que se han desarrollado en etapas recientes.

Son muchos los alumnos que llegan a la Universidad con graves problemas ortográficos, gramaticales y léxicos y con serias dificultades para redactar un texto, por sencillo que este sea. ¿Cuántos universitarios acentúan con el criterio de corrección que nace de las normas establecidas en la última edición de la Ortografía de la lengua española de la Asociación de las veintidós Academias, publicada en diciembre de 2010? Lo preocupante es que la ignorancia para poner las tildes, con criterio normativo, se manifiesta en la escritura de cualquier tipo de textos; sean estos administrativos, jurídicos, científicos, técnicos, publicitarios, humanísticos, periodísticos o literarios. Los resultados demuestran que no se aplica de forma correcta la norma académica y que, en muchos casos, no se tienen en cuenta los cambios que aparecieron en la edición de la Ortografía española de 1999, ni los incorporados en el Diccionario panhispánico de dudas de 2005. Dichos resultados precisan que en el campo de las letras hay que regular y sistematizar de modo riguroso el uso de las mayúsculas para evitar la tendencia a la mayusculización, sin criterio científico alguno. En la Ortografía española de la Asociación de las veintidós Academias de la Lengua Española (16 de diciembre de 2010) se soluciona, en gran parte, el problema.

En lo que se refiere a la acentuación, la deficiencia más notable se presenta en los hiatos. Hay que prestar especial atención a este subapartado. Para ello, hay que dejar clara la solución tal y como se hace en la edición de la Ortografía española de 2010. Los hiatos de dos vocales cerradas iguales (como el caso señalado de chiita o chiismo) siguen las reglas generales de la acentuación. La Real Academia, después de haber errado en el DRAE (21. a: 1992), donde aparecía * chiíta, rectificó en la Ortografía de 1999 y en la vigésima segunda edición del Diccionario de la lengua española (22. ${ }^{a}$ ), en 2001. Y, antes, en la edición del Diccionario escolar de 1996. Por esta razón, no se acentúa chiita y sí lleva tilde chií. La combinación de dos vocales cerradas distintas, caso de jesuita, se considera como diptongo a los efectos de la tildación. Los hiatos compuestos de dos vocales abiertas, iguales o distintas (aéreo o Feijoo), también siguen las reglas de acentuación, mientras que no lo hacen los hiatos compuestos de vocal abierta y vocal cerrada tónica o vocal cerrada tónica y vocal abierta (baúl, púa), donde la función de la tilde es la de señalar que el diptongo se ha roto y, en su lugar, hay hiato; en este caso, hiato inverso.

La problemática de la puntuación (actualmente dirigimos un proyecto de investigación sobre la historia de la puntuación del español, financiado por el Instituto Universitario de Investigación de la Fundación Ortega y Gasset-Marañón) debe abordarse atendiendo a tres preguntas: para qué puntuar, cómo puntuar y por qué puntuar. Ello significa que hay que conocer las funciones de la puntuación y los contextos que la requieren. La puntuación es un factor esencial en la vertebración, organización y cohesión de los textos. De ahí, el valor de los signos de puntuación 
como organizadores textuales. Por esta razón, tras señalar los principales errores en el uso de este componente ortográfico tan decisivo en la arquitectura textual, los resultados demuestran que es necesario estructurar una clasificación de los signos de puntuación de manera más sistemática, que tenga en cuenta la orientación pragmáticocognoscitiva. Puntuar bien un texto es un indicio de rigor mental, claridad de ideas y conocimiento del funcionamiento sintáctico (y pragmático) de la lengua.

Puntuar mal es, por el contrario, indicio de desorden mental, de ignorancia de la teoría y de la práctica de la sintaxis. Por tanto, el resultado final en el análisis de esta parte de la ortografía precisa que hay que evitar los problemas de puntuación, con el fin de facilitar la comprensión a los destinatarios de los textos y no crear ambigüedades. Para ello, hay que considerar, además del valor de la información sintáctico-semántica y fónica, el valor de la información pragmática que nos proporciona este componente de la ortografía; hecho que ha quedado claro en nuestro estudio. De este modo, los contenidos se estructuran de manera imprecisa, con la consiguiente presencia de incoherencias, ambigüedades y anomalías sintácticas.

La competencia léxica es otro apartado que merece atención especial. Entre los profesores de Lengua Española de los diversos niveles educativos, la pobreza de vocabulario de los alumnos es un hecho que causa una gran preocupación (M. Alvar: 2003). Los alumnos de Bachillerato conocen, por término medio, el significado de unas cuatro o cinco mil palabras. En otros casos y circunstancias socioculturales, la cantidad puede bajar hasta las mil quinientas o las dos mil palabras. Para hacer esta valoración, hay que considerar que una persona culta conoce el significado de unas veinte mil palabras. Menos de una cuarta parte de las que tiene el DRAE (22. ${ }^{\mathrm{a}}$ : 2001.88431 lemas), y la mitad de las más de 40000 palabras y locuciones del léxico vivo del español que presenta el diccionario escolar, elaborado por la RAE y la Asociación de Academias de la Lengua Española para el nivel de la Enseñanza Secundaria y Bachillerato, el Diccionario del estudiante (2011, última edición). El Diccionario práctico del estudiante (2007) tiene unas 30000 palabras y locuciones del léxico vivo del español.

Si no se lee, si no se escribe, los resultados no pueden ser satisfactorios. La pedagogía debe empezar por leer más en las escuelas y en los institutos, por hacer ejercicios de composición, por conjugar los verbos, por distinguir un sustantivo de un adjetivo, por identificar y conocer las diferentes categorías sintácticas (determinantes, sustantivos, adjetivos, pronombres, verbos, adverbios, preposiciones, conjunciones e interjecciones), por conocer los elementos de relación y marcadores discursivos, con la finalidad de que la conexión y el engarce de los párrafos sean los adecuados.

La lengua española debe adaptar su metodología a las orientaciones y principios didácticos que aparecen estructurados en el documento correspondiente al Marco Común Europeo de Referencia para las Lenguas (2001, 2002), con el propósito de mejorar los resultados en los diversos ámbitos y niveles de la enseñanza desde la Enseñanza Obligatoria a la Universidad. El modelo pedagógico tiene que enfocar, necesariamente, los saberes y conocimientos propios al desarrollo y uso de las cuatro destrezas comunicativas receptivas: comprensión lectora y comprensión auditiva, productivas: expresión escrita y expresión oral, interacción y mediación.

El Marco Común Europeo de Referencia para las Lenguas: Aprendizaje, Enseñanza y Evaluación es un documento cuya finalidad es la de proporcionar una formación integral para la creación de programas de lenguas, orientaciones metodológicas, exámenes, materiales didácticos y técnicos. El objetivo principal es 
facilitar la comunicación y la movilidad entre los distintos países europeos tanto en lo se refiere al ámbito educativo como al ámbito profesional.

Los niveles de competencia comunicativa estructurados y sistematizados en el MCERL son Usuario básico (A1 y A2), Usuario independiente (B1 y B2) y Usuario competente ( $\mathrm{C} 1$ y $\mathrm{C} 2)$.

En relación con este proceso, hay que hacer la valoración del Portafolio europeo de las lenguas. Este otro documento, impulsado por el Consejo de Europa, tiene tres apartados:

1. ${ }^{\circ}$ Pasaporte de las lenguas. En esta parte, se refleja la competencia comunicativa por destrezas: comprensión lectora, expresión escrita, comprensión auditiva, expresión oral (donde integra la interacción). También se señalan los cursos realizados y los diplomas conseguidos.

2. ${ }^{\circ}$ Recoge las experiencias lingüísticas de formación de cada uno de los alumnos.

3..$^{\circ}$ Memoria en la que el alumno guarda sus trabajos, con el fin de demostrar los niveles de su competencia comunicativa, llegado el momento.

El español y su literatura tienen que estar integrados, plenamente, en el rico patrimonio de las lenguas, literaturas y culturas europeas, con el objetivo de cooperar a la movilidad internacional y facilitar la comunicación entre los europeos. Este proceso se convertirá, de esta manera, en un medio eficaz para el logro de los objetivos educativos, docentes, investigadores y profesionales.

\section{OBjetivos}

La metodología de la asignatura de Lengua Española en los niveles de la Segunda Enseñanza, dado que, como hemos señalado, los resultados obtenidos no son enteramente satisfactorios, debe atender, por tanto, a las siguientes orientaciones:

1. Hay que programar de forma equilibrada la teoría lingüística, de manera que esté enfocada en función de la práctica y, en concreto, del método comunicativo, con objeto de que los alumnos aprendan las destrezas necesarias para construir textos orales y escritos de diversa naturaleza. "No hay nada que tenga para la enseñanza tanta virtud como el ejemplo", señalaba el lingüista gaditano en el vol. I de la Arquitectura de las lenguas (1889: 13).

2. Por tanto, la asignatura de Lengua Española debe partir de una orientación descriptiva y de una perspectiva pragmático-comunicativa con el propósito de estudiar la lengua real en todas sus dimensiones.

3. Hay que evitar planteamientos metodológicos erróneos, de forma que las definiciones, reglas y explicaciones resulten claras y no causen confusión entre los alumnos. Cuando estas definiciones resultan poco explícitas y equívocas y son expresadas en términos vagos, difícilmente precisables, el objetivo principal en el proceso-enseñanza de la lengua sale perjudicado, gravemente.

4. La memorización de estas definiciones no conduce a cumplir los objetivos encaminados al dominio de la expresión oral y escrita.

5. En las clases hay que trabajar con textos escritos y orales de distinta tipología y naturaleza, por lo que resulta fundamental orientar la metodología con la aplicación de las nuevas tecnologías en las aulas. 
6. Los ejercicios de expresión escrita y de expresión oral deben estar equilibrados en la programación de las diversas unidades didácticas. Las normas y reglas que proponen los manuales tradicionales no coinciden con la realización de la lengua hablada o escrita realmente usual. La primera gramática, en verdad, moderna del español, los Breves apuntes sobre los casos y las oraciones (1853) de Eduardo Benot, es el mejor testimonio de una obra ejemplar en lo que se refiere a la prioridad de la práctica idiomática sobre una teoría atosigante y que nada resuelve en la mejora de la expresión tanto oral como escrita.

7. La gramática debe estudiarse en estrecha relación con los demás planos de la lengua y, por tanto, en función de esta y no al contrario. La orientación teórica, teórico-práctica y práctica debe estar adecuadamente equilibrada para conseguir los resultados deseados.

8. Hay que procurar que estas afirmaciones de M. ${ }^{a}$ Dolores Poch Olive no sigan teniendo actualidad en la enseñanza de la lengua (1983): "Si consultamos los libros de texto con los que normalmente se trabaja vemos que los ejercicios propuestos por los autores deben realizarse, en general, por escrito. Se trata, en muchas ocasiones, de comentarios de texto y, en el mejor de los casos, de redacciones, mientras están ausentes ejercicios sobre el aspecto oral de la lengua". Benot también es un precursor de esta concepción en la que la relación de los interlocutores con el código es primordial para favorecer el desarrollo de los actos comunicativos. Una metodología consecuente debe prestar atención a la mejora del uso de las destrezas escribir y leer, pero, al mismo tiempo, a las destrezas hablar y escuchar. El centrar el estudio de la lengua sólo en el análisis de los textos escritos ha sido un grave error.

9. Hay que evitar la teorización de un concepto de norma rígido, ya que este no ha favorecido, precisamente, la creatividad y producción de textos escritos y orales. El logro de las destrezas leer y escribir, escuchar y hablar, y en relación con esta última, la interacción, debe ser el resultado aplicado de una lingüística comunicativa que integre y coordine la competencia ortográfica, la competencia fónica, la competencia gramatical, la competencia semántica, la competencia léxica, la competencia literaria, la competencia pragmática, la competencia sociolingüística, la competencia psicolingüística y la propia competencia paralingüística.

10. Las referencias a las diversas áreas lingüísticas del español europeo y americano y a las variedades diastráticas y diafásicas deben constituir una cuestión prioritaria en la enseñanza del español en los diversos niveles, desde la escuela a los estudios superiores.

11. No se puede confundir, en ningún momento, la enseñanza de la lengua con la enseñanza de la gramática, ya que enseñar gramática no es enseñar lengua, sino cuestiones sobre la lengua. Son hechos diferentes que como tales persiguen finalidades diferentes. La gramática debe centrar sus objetivos en el análisis de la estructura de las palabras (morfología) y en el análisis de las estructuras que se crean en función de la forma en la que se ordenan y se combinan las palabras (sintaxis). Así se señala en la presentación de la Nueva gramática de la lengua española (2009) de la RAE y de la Asociación de Academias de la Lengua Española.

12. El enfoque de la gramática debe ser descriptivo, con la concepción de la lengua como instrumento de comunicación y del texto como unidad comunicativa 
fundamental. La teoría gramatical debe tener como objetivo la construcción de textos orales y escritos de diversa naturaleza y la competencia lingüística, dar respuesta a las dudas y dificultades sobre cuestiones normativas, así como sobre la descripción de las construcciones gramaticales propias del español general. Esta interrelación facilitará, así, la tarea encaminada a que los alumnos conviertan la gramática en un medio eficaz para mejorar su competencia comunicativa, al partir del uso lingüístico como factor imprescindible en el estudio de lengua en sus diversos contextos comunicativos.

13. El corpus de materiales sobre el que se realiza la descripción de los hechos lingüísticos debe pertenecer a una rica variedad textual y, por consiguiente, la misma debe reflejarse a través de la diversidad tipológica. Quien haya leído el Arte de hablar. Gramática filosófica de la lengua castellana (1910) lo entenderá sin duda alguna.

14. Y esto es así, porque pretender regular el habla a partir de los textos literarios resulta abusivo y radicalmente inadecuado. Los estudiosos que hayan leído y analizado el discurso de entrada en la Real Academia de Eduardo Benot, ¿Qué es hablar? (1889), sacarán las oportunas conclusiones sobre el hecho de que un hecho es enseñar (aprender) lengua y otro muy distinto enseñar cosas (cuestiones más teóricas que prácticas) sobre la lengua.

15. Recordemos en relación con ello las siguientes afirmaciones que hace E. Benot (1889: 12-13): “Ahora se comprenderá por qué no enseñan las infelices gramáticas que tienen por exclusivo objeto las palabras: ahora se hará patente por qué, como cizaña en tierra de pan sembrar, esquilman las más tenaces memorias".

16. Del análisis y del estudio de los Breves apuntes sobre los casos y las oraciones preparatorios para el estudio de las lenguas (1853), la Arquitectura de las lenguas (1889), el discurso de entrada en la RAE, ¿Qué es hablar? (1889), y del Arte de hablar. Gramática filosófica de la lengua castellana (1910) se deduce que la concepción lingüística y gramatical de Benot supera, definitivamente, una enseñanza del español basada en la gramática (y, en relación con la misma, solo en la lectura y en la escritura), para centrar sus objetivos, sin descuidar la lengua escrita (y, en particular, la literaria), en la lengua oral, lo que lo convierte en un antecedente de los modernos estudios de pragmalingüística y de análisis del discurso, además de la gramaticalización, con aplicaciones tan fructíferas a la enseñanza de las lenguas y, en particular, a la enseñanza del español como lengua materna.

De acuerdo con estos objetivos, hay que considerar en la didáctica de la lengua española en la Enseñanza Secundaria los siguientes principios teóricos y teóricoprácticos:

A. El principio de que una lengua es un instrumento de comunicación.

B. La capacidad y habilidad para usar la lengua.

C. El concepto de competencia comunicativa (la capacidad de usar la lengua por los hablantes, pero teniendo en cuenta el hecho fundamental de que, unida a tal capacidad, está la habilidad de adaptar el uso al contenido o situación de habla) y, en relación con la misma, el estudio de las competencias (o saberes) lingüísticas: ortográfica, gramatical, semántica, léxica y textual. 
D. De ello se deduce que el alumno-hablante debe ser adiestrado no sólo en el conocimiento gramatical de la lengua, sino también en el manejo de la misma en sus diversas modalidades y estilos funcionales.

E. El tener la habilidad para pasar de un estilo o registro funcional a otro.

F. La necesidad de operar con el significado contextual y pragmático.

G. Y todo ello argumentado y basado en la preocupación por los aspectos pragmáticos de la comunicación $y$, en consecuencia, por la atención al sentido y al fin elocutivo.

H. La atención al contexto y a la situación y a la relación de los usuarios de la lengua con el código.

I. La necesidad de incorporar a la metodología las relaciones entre la sintaxis y la pragmática y, en relación con este aspecto, las intenciones comunicativas de los hablantes.

J. La concepción moderna de la gramática, al llegar de la palabra a la oración y de esta a la cláusula y al texto como unidad comunicativa; en definitiva, al convertir la gramática en una gramática sintáctica, sintáctico-semántica, sintáctico-léxica, sintáctico-discursiva y sintáctico-pragmática.

$\mathrm{K}$. Al defender una concepción que entiende la gramática como una gramática comunicativa y cognitiva, donde el componente sintáctico y el semántico resultan principales, hay que considerar en la didáctica de la lengua los estudios actuales de pragmalingüística y de análisis del discurso, por la utilidad de sus aplicaciones.

L. La orientación de la enseñanza de la lengua española a actividades de formación como el logro de destrezas y habilidades para hablar en público, redacción de textos escritos de distinta tipología.

M. Estudio de los textos escritos:

1. Por su modalidad o tipo de secuencia discursiva predominante: argumentales, descriptivos, expositivos, instructivos, narrativos.

2. Por su temática o ámbito de uso: académico: exámenes, informes, presentaciones, trabajos, proyectos, tesis; literarios: carta literaria, cuento, ensayo, novela, novela corta, obra de teatro, poema, relato; periodísticos: de opinión: artículo y editorial, de información: noticia; interpretativos: crónica y reportaje; humanísticos: antropológicos, filológicos, filosóficos, históricos, sociológicos; políticos: bandos, discursos, manifiestos; publicitarios: anuncios, eslóganes, folletos; jurídicos: demandas, leyes, reclamaciones, recursos, sentencias; administrativos: actas, alegaciones, certificados, circulares, contratos, declaraciones juradas, denuncias, escrituras, formularios, instancias, oficios, resoluciones; médicos: historias clínicas, informes, prospectos, recetas; técnicos: artículos e informes técnicos relacionados con la arquitectura, informática, ingeniería; científicos: artículos científicos, informes científicos, monografías o artículos relacionados con la astronomía, biología, botánica, física, matemáticas, química; vida cotidiana: avisos, correspondencia, indicadores, letreros, notas, postales, tarjetas.

N. Estudio de los textos orales en la diversidad de su manifestación, tanto si son dialogados o dialógicos (coloquio, conversación, debate, entrevista, 
mesa redonda, tertulia) como si son monologados (charla, clase, conferencia, discurso, mitin, presentación).

Ñ. De la misma manera, hay que estructurar la clasificación de acuerdo con la función del lenguaje que predomine: apelativos (conversación, diálogo, entrevista, coloquio, mesa redonda), explicativos (exposiciones didácticas, manuales, solucionarios de ejercicios), informativos (artículos, carteles, crónicas, diagramas), persuasivos (anuncios publicitarios, artículos de opinión, cartas publicitarias, carteles publicitarios, editoriales), prescriptivos (avisos, circulares, consignas, contratos, recetas, disposiciones legales, resoluciones), poéticos o literarios (cuentos, ensayos, historietas, humor, novelas, obras de teatro, poemas, relatos). Respecto a esta cuestión, conviene aclarar que no existe una clasificación única de los textos, pues en uno mismo pueden confluir aspectos, funciones del lenguaje o características propias de otros. Así, en un texto podemos encontrar secuencias argumentativas, descriptivas, expositivas o narrativas. La heterogeneidad de un texto y, en consecuencia, su hibridismo son puntos que hay que considerar en relación con su estudio y análisis teórico, teórico-práctico y práctico.

O. La consideración en la enseñanza de las lenguas (y no solo del español) de un método, esencialmente, práctico e interactivo, en el que la lengua oral debe desempeñar una función principal; todo lo contrario que habían defendido las gramáticas de orientación tradicional, entre ellas las de la RAE hasta 1931, y, asimismo, los manuales, compendios y epítomes, nacidos de estas.

P. Por tanto, en la interrelación de las diversas competencias lingüísticas (ortográfica, fónica, gramatical, semántica, léxica), pragmática, textual y de otras competencias (sociolingüística, psicolingüística y paralingüística) están las bases y los cimientos de un método comunicativo, funcional y pragmático en la enseñanza de la lengua, en el que la descripción desplaza a la prescripción y al modelo heredado de la lingüística grecolatina y en el que sus principios metodológicos superan los sustentos teóricos de la concepción de la llamada gramática tradicional como "arte de hablar y escribir correctamente" (Peñalver 1993 y 1995). De esta manera, la competencia lingüística va a resultar fundamental, pero siempre que la misma actúe en función de lo que, en realidad, importa: la competencia comunicativa y su concreción en la mejora de la expresión escrita y de la expresión oral de los alumnos de los diversos niveles educativos, incluida la Universidad.

Q. La importancia decisiva del contexto en el significado y, por consiguiente, en la necesidad metodológica de analizar y estudiar el significado contextual y, de acuerdo con este presupuesto, la lengua real. Ello implica, asimismo, una especial atención a aquellos factores extralingüísticos que inciden e influyen en el uso de la lengua como instrumento de comunicación. Este proceso de concebir el estudio de la lengua conduce a una metodología en la que la definición tradicional de la gramática como "arte" queda desplazada por otros planteamientos que, como hemos señalado, van a configurar los antecedentes de la pragmática y del análisis del discurso; de la oralidad, en suma.

R. Estas orientaciones adquieren, así, un sentido práctico, cuyas consecuencias metodológicas tienen una clara aplicación a la redacción y composición de textos escritos y orales de distinta naturaleza y cuyos mecanismos discursivos 
pueden resultar de un gran interés para organismos oficiales, instituciones, partidos políticos, medios de comunicación, en general, empresas y particulares. Anuncios, artículos, campañas electorales, cartas, circulares, coloquios, comunicados, conferencias, currículum vitae, debates, diapositivas en powerpoint, diseño de transparencias, discursos, documentos, informes, libros de estilo, memorias, notas de prensa, páginas web, proyectos, tertulias, tesinas y tesis doctorales y cualquier tipo de texto (científico, técnico, publicitario, jurídico, administrativo, humanístico, periodístico, literario) pueden salir reforzados con las aplicaciones teórico-prácticas de las estrategias comunicativas que emanan de las obras gramaticales, ya citadas, de Benot.

S. En este aspecto, la construcción de textos (orales y escritos), donde el texto sea considerado como la unidad comunicativa básica, debe considerar la adecuación, coherencia y la cohesión, los registros (coloquial, estándar, técnico, literario, culto), las variedades, las estrategias comunicativas y la ordenación de la información y otras cuestiones pragmáticas y discursivas que ayuden y sirvan para conseguir los fines propios de la teoría y de la práctica idiomática. De modo que los usuarios de la lengua se pregunten, de forma reflexiva, no sólo ¿qué es leer?, ¿qué es escribir?, sino también ¿qué es hablar?, ¿qué es escuchar?

T. Para el logro de estos objetivos, la teoría gramatical debe partir de tres premisas básicas: Determinar; Conexionar; y Enunciar. Pero, además, hay que estudiar, con el máximo rigor, el español en internet, el español de los negocios, el español de la economía y, en general, el español de las llamadas lenguas profesionales: académica, administrativa, científica, jurídica, médica, periodística, publicitaria, política, técnica, tecnológica. La mejora de la enseñanza de la asignatura de Lengua resulta, pues, esencial para el logro de una competencia comunicativa eficaz y adecuada a las diversas situaciones y fines específicos. "Hablar es sacar a las palabras de su generalidad, limitando con otras palabras su extensión y generalidad", E. Benot (1889: 18). "El conocimiento de la vida de las palabras exige, pues, estudio continuo y laborioso", E. Benot (1889: 24). No olvidemos que François Bacon decía: "La lectura hace al hombre completo; la conversación, ágil; y el escribir, preciso". Ni tampoco que Arquímedes de Siracusa señalaba: "El que sabe hablar, sabe también cuándo".

\section{ANÁLISIS POR COMPETENCIAS}

La enseñanza de la lengua española, en relación con el Marco Común Europeo de Referencia para las Lenguas: Aprendizaje, Enseñanza, Evaluación, debe basarse en la estructuración y sistematización de las diversas competencias (Pilleux 2001):

1. Competencia ortográfica (letras, acentuación, puntuación, ortografía técnica y otras cuestiones), con la Ortografía de la lengua española (2010) de la RAE y de la Asociación de las 22 Academias de la Lengua Española como referencia principal.

2. Competencia fónica (fonética, fonología, entonación).

3. Competencia gramatical, con la Nueva gramática de la lengua española, I vol. 
de morfología y sintaxis (2009), II de sintaxis (2009) y el tercero de fonética y fonología (2011), de la RAE y la Asociación de las 22 Academias de la Lengua Española, el Manual de la nueva gramática de la lengua española (2010) de la RAE y de la Asociación de las 22 Academias de la Lengua Española y la Nueva gramática básica de la lengua española de la RAE y la Asociación de las 22 Academias de la Lengua Española como especiales referentes.

4. Competencia semántica.

5. Competencia léxica.

6. Competencia lexicográfica.

Además, en relación con las mismas, la competencia pragmática, la competencia sociolingüística, la competencia psicolingüística, la competencia paralingüística, la competencia literaria y la competencia textual. Estos conceptos reclaman definiciones precisas, con la finalidad de aproximarnos a su campo de estudio (Pilleux 2001, Álvarez 1995).

La suma de todas estas competencias, en el componente teórico, teórico-práctico y práctico, debe dar como resultado el logro de una competencia comunicativa que sirva para el desarrollo y dominio de las cuatro destrezas: hablar y escuchar; leer y escribir, o sea: expresión oral y expresión escrita, comprensión oral y escrita, con el fin de llegar al nivel más avanzado, como se indica en el Marco Común Europeo de Referencia para las Lenguas: Aprendizaje, Enseñanza, Evaluación (MCERL).

El estudio de la fonética, de la fonología y de la entonación (estudio o análisis de la línea melódica de los mensajes, variedad de tonos, tonema, información sobre la modalidad oracional, pragmática: intenciones comunicativas: ironía, afecto, sorpresa, incertidumbre. No siempre una oración interrogativa termina en un tonema ascendente y una afirmativa en una tonema descendente) debe constituir el objetivo de la competencia fónica.

El análisis de las letras (donde hay que estudiar con rigor la correspondencia entre letras y fonemas, sobre todo en los casos del fonema interdental fricativo sordo -letras c y z-, del velar fricativo sordo -letras j y g-, del velar oclusivo sordo -uso de las letras $\mathrm{c}, \mathrm{k}$ y del dígrafo qu-, del fonema velar oclusivo sonoro -uso de la letra $\mathrm{g}$ y del dígrafo gu-, del fonema vibrante múltiple -letras $\mathrm{r}$ y del dígrafo rr-), de la acentuación, de la puntuación, de las abreviaturas, de la llamada ortografía técnica constituye el motivo de estudio de la competencia ortográfica.

Las variaciones de las palabras: género, en los sustantivos, adjetivos, pronombres y determinantes; número, en los sustantivos, adjetivos, pronombres y determinantes, con las características propias, que dan lugar a subclases, y verbos; grado, en los adjetivos, y modo, tiempo, persona y aspecto en los verbos (morfología flexiva), la estructura de las palabras y los mecanismos de su formación (morfología léxica o derivativa), la combinación de las categorías y grupos sintácticos (sintaxis) y las consecuencias sintácticas tanto de la morfología flexiva como de la morfología derivativa conforman la razón de ser de la competencia gramatical. Las preposiciones, las conjunciones, los adverbios y las interjecciones, al no tener capacidad flexiva, son considerados como categorías sintácticas invariables. En lo que concierne a los paradigmas flexivo y derivativo, hay que señalar que formas como cant-a-ba o cant-é son variantes de una misma palabra y, por el contario, formas como librería o librero (derivadas de libro) son palabras diferentes. 
El significado lingüístico nos lleva al campo de la semántica; el estudio de las formas en que se organizan los significados lingüísticos, a la lexicología, y el uso que hacen los hablantes de los recursos idiomáticos, a la pragmática. Así se afirma en la Nueva gramática de la lengua española. La concepción de la lengua como instrumento de comunicación es el punto de punto de partida y, también, el punto de llegada.

De este enfoque no pueden estar ausentes las funciones informativas que determinan, como igualmente se manifiesta en la Nueva gramática de la lengua española, la aplicación de las funciones sintácticas y semánticas al discurso, con la intención de determinar si el contenido que aportan se interpreta como información nueva (o remática) o se da ya por conocida (o temática).

Los objetivos solo se cumplirán si el estudio de los contenidos del temario se reflejan en la práctica idiomática y ello nos permite, por un lado, reconocer e identificar las variedades geográficas, los niveles de lengua y los registros y estilos lingüísticos y, por otro, estar preparados para descubrir las construcciones agramaticales, anómalas o incorrectas.

Entre las incorrecciones podemos citar estructuras y usos como los siguientes: *este área en lugar de esta área, *ambos en lugar de sendos, *pienso de que (dequeísmo) en lugar de pienso que, *estoy seguro que (queísmo) en lugar de estoy seguro de que, *una poca agua en lugar de un poco de agua, leísmo, laísmo y loísmo en lugar de las estructuras sintácticas correctas, *yo me parece (yoísmo) en lugar de a mí me parece, he llegado (pasado cercano al presente) en lugar de llegué (pasado distante del presente), *preveer en lugar de prever, adolecer en lugar de carecer, *satisfacería en lugar de satisfaría, *cesar en lugar de destituir, *incautar en lugar de incautarse, *sentaros en lugar de sentaos, *habían muchas personas en lugar de había muchas personas, *hicieron unos días muy buenos en lugar de hizo unos días muy buenos (o sea, la pluralización de los verbos haber y hacer cuando actúan como impersonales), *se alquila pisos en lugar de se alquilan pisos, *deber de+infinitivo en lugar de deber+infinitivo para expresar la obligación, *es por eso que en lugar de por eso, el pronombre relativo que en lugar de otros pronombres relativos, *la decisión a tomar en lugar de la decisión que hay que tomar, *detrás mío en lugar de detrás de mí, *porqué en lugar de por qué (o al contrario), *sino en lugar de si no, el abuso de los adverbios en mente, anacolutos de diversa tipología (falta de ilación en la sintaxis), usos anómalos (como el del gerundio, entre otros), que afectan al empleo adecuado de las categorías sintácticas (Peñalver 1998, Seco 2011).

El punto de encuentro de la enseñanza de la materia de Lengua Española debe ser, pues, la competencia comunicativa. La misma ha de entenderse como la capacidad de usar la lengua que tienen los hablantes, pero teniendo en cuenta el hecho fundamental de que, unida a tal capacidad, está la habilidad de adaptar el uso al contenido o situación de habla. En relación con la misma, está el concepto de competencia lingüística, saberes o conjunto de saberes sobre la lengua en el campo ortográfico, fónico, gramatical, semántico, léxico y textual. El texto debe ser considerado como la unidad comunicativa por excelencia y, en torno al mismo, deben girar las competencias lingüísticas mencionadas. Consultemos a este respecto las obras de D. Cassany, M. Luna y G. Sanz (2008), R. A. Vegas (2009) y L. Gómez Torrego (2011).

De acuerdo con todo lo expuesto, consideremos la relevancia pedagógica de seguir investigando en un campo, de tanta utilidad didáctica para la enseñanza de la asignatura de Lengua Española en la ESO y en el Bachillerato, como es el correspondiente a las ortografías, gramáticas y diccionarios escolares. No puede 
pasar desapercibido el hecho de que en las dos últimas décadas ha habido notables avances, ni que un estudioso de tanto prestigio como L. Gómez Torrego oriente sus publicaciones en este ámbito. Las últimas ediciones de su Gramática didáctica del español (2011), su Ortografía (2011), su Análisis morfológico. Teoría y práctica (2011) y su Análisis sintáctico. Teoría y práctica (2011), con una variada y rica propuesta de ejercicios, con soluciones, son la confirmación de que la contribución al progreso del conocimiento en este campo es esperanzador.

La competencia literaria debe ser en el proceso de enseñanza-aprendizaje de la lengua española un elemento decisivo e imprescindible para enriquecer la competencia comunicativa, dada la variedad de recursos lingüísticos que aparecen en los textos literarios y los mecanismos de cohesión de los mismos. Por esta razón, en esta parte de los contenidos tratamos los fundamentos de la misma. La competencia literaria debe ser considerada como un saber o conocimiento que permite comprender y producir textos literarios, leerlos, interpretarlos y construirlos. El objetivo debe ser, por ello mismo, elaborar y abordar un método que integre y sistematice las destrezas o capacidades señaladas con la pretensión de aplicarlas a los contenidos de la materia de Literatura en la Enseñanza Secundaria.

Todos estos presupuestos demuestran la necesidad de integrar la competencia literaria, de forma equilibrada y gradual, en la propia competencia comunicativa, en consonancia siempre con el desarrollo de la competencia lectora en sus tres apartados (lectura comprensiva, lectura interpretativa, lectura reflexiva), de la competencia para escribir textos literarios (en cualquiera de sus tipologías), para debatir o escribir sobre cualquier cuestión relacionada con un texto literario o una obra literaria, para conocer los distintos períodos o épocas de la historia de la literatura, los autores seleccionados en la programación, para valorar y comentar los valores sociológicos, históricos, culturales y, por supuesto, lingüísticos y estilísticos de dichas obras o textos. Y ello mismo, con el propósito de enriquecer no solo la competencia comunicativa, sino la misma formación integral de aspectos tan relevantes y de tanta significación en la educación y en la enseñanza.

El profesor de lengua materna debe poseer, como ya se ha señalado, una sólida preparación científica en los principios de la lingüística y, por consiguiente, en la norma; y todo ello porque en la enseñanza de esta asignatura no se deben adoptar desde el punto de vista normativo ni las posturas rígidas de la gramática tradicional ni otras posturas anárquicas y permisivas, que tampoco se caracterizan por su positiva aportación a la didáctica del español como lengua materna. Así, es necesario precisar que

Hoy se intenta fijar esta norma o este conjunto de reglas prescriptivas, de un modo totalmente objetivo, partiendo de la descripción de las estructuras lingüísticas de la lengua en cuestión y tomando como tales las que sean aceptadas por el uso o establecidas por los técnicos, siempre que reposen sobre un código lingüístico aceptado socialmente como bueno. A esta norma así establecida se podrán referir las cuestiones de corrección en todos los niveles de la lengua (Quilis 1978: 28).

También así lo manifiesta M. ${ }^{a}$ T. Vaquero (1978: 146): "Si logramos conocer el valor que los hablantes dan a los fenómenos lingüísticos habremos dado un paso adelante en la búsqueda de la norma, y este español basado en la norma de la sociedad que lo maneja es el español que defiendo, sin descuidar las demás manifestaciones". Como afirma esta misma investigadora, reconocer todos los niveles y variedades 
del sistema, en su complejidad diatópica y diastrática, y admitir la jerarquización de los fenómenos lingüísticos, es lo que puede salvarnos del purismo y del anarquismo irresponsable.

La enseñanza de la lengua española en las etapas obligatorias de escolaridad está muy lejos de alcanzar los objetivos mínimos exigidos. Los métodos de dicha enseñanza-aprendizaje han demostrado de manera evidente su inadecuación y fracaso, salvadas todas las honrosas excepciones. Las destrezas de comprensión y expresión oral y escrita de los alumnos son insuficientes. Uno de los principales factores del fracaso escolar en dichas etapas se debe de manera importantísima a su escaso conocimiento de nuestra lengua, a que no saben expresar los conocimientos que han estudiado. No comprenden, en muchísimas ocasiones, lo que el profesor les explica porque no han logrado una adecuada competencia lingüística ni comunicativa y menos aun pragmática en su comunicación cotidiana. Por ello mismo, es primordial intentar resolver esta situación modificando, reajustando y precisando los objetivos. Las numerosas reformas oficiales de los últimos lustros, bien intencionadas generalmente, son limitadas en diversos aspectos y, sobre todo, demasiado generales y aun ambiguas. Faltan materiales didácticos e instrumentales para la enseñanza desde las nuevas perspectivas. Tampoco se ha propiciado suficientemente una preparación sólida y actualizada del profesorado. La enseñanza de la lengua española -hay que insistir en ello- viene siendo un fracaso.

La lectura y análisis del texto del Marco Común Europeo de Referencia para las Lenguas (MCERL) debe ser el punto de partida de un método comunicativo, funcional, productivo y creativo; y todo ello, desde el convencimiento de que el eje y protagonista de todo esto es el alumno; es decir, que el método ha de ser esencialmente activo, participativo, dinámico, que busque el saber aprender como propósito principal.

El objetivo de la enseñanza de la lengua española debe ser el dominio de los mecanismos y recursos de expresión y comprensión en la comunicación oral y escrita, así como de otros sistemas comunicativos, en todo tipo de interacción. Su logro implica poseer una adecuada competencia lingüística, una competencia pragmática, una competencia sociolingüística y una competencia textual, como hemos señalado.

Estamos hablando de un método que enseñe no sólo a hablar, sino a comunicarse debidamente, en toda su plenitud, en cualquier circunstancia y contexto. Nada, pues, que ver con los tradicionales métodos emanados de la lingüística inmanentista de cualquier color, aun cuando en ocasiones haya que recurrir a algunos de sus conocimientos más útiles. Si cualquiera de nosotros aprendiera una lengua extranjera, adquiriendo solamente una debida competencia del sistema interno de esa lengua, y nada más, probablemente no estaría capacitado para comunicarse en diferentes situaciones sociales ni en diversas circunstancias.

Todos estamos convencidos de que no hablamos por "oraciones" y de que la comunicación no consiste en ensartar una serie de oraciones aprendidas de memoria, como en absoluto podemos interpretar que la lengua sea una sarta de palabras sin ningún tipo de conexión ni cohesión. La comunicación es algo mucho más complejo, posiblemente una de las cosas más complejas y difíciles de la vida. Nosotros utilizamos la lengua y la aprendemos para poder comunicarnos con cualquier persona en cualquier situación y contexto. Ese saber adecuar nuestra elocución a nuestros intereses, a las circunstancias, al interés del interlocutor es saber usar una lengua. Todo método de enseñanza de una lengua debe ser productivo, creativo, que enseñe 
a producir mensajes, además de a interpretarlos, más a combinar enunciados que a segmentarlos, más a crearlos que analizarlos.

¿Qué lengua enseñar? Hay que respetar las variedades diatópicas y sociales en la comunicación; pero es imprescindible que el eje y centro de la enseñanza-aprendizaje de la lengua en los niveles de Primaria, Secundaria y Bachillerato, sea el español llamado estándar. El español en el que los alumnos van a adquirir casi todos sus conocimientos académicos o no, el que van a necesitar para cualquier comunicación formal; en el que van a recibir todo el flujo cultural.

A partir de ciertos niveles de estudios, habrá que reflexionar con los alumnos sobre los diversos usos sociales y su adecuación a unas u otras situaciones comunicativas, mas sin dejar de insistir en los usos beneficiosos, en los simbólicos, frente a los no adecuados. Esos usos beneficiosos son los que ofrecen mayor disponibilidad léxica, riqueza sintáctica y semántica y abundancia de esquemas discursivos. Nunca debemos olvidar que la enseñanza en estos niveles tiene que enseñar y hacer aprender todas las carencias que los alumnos tienen de su lengua.

No debemos olvidar que toda lengua es un conjunto de variedades geográficas y sociales, entrecruzadas, pero por encima de ellas está la norma común de la cultura o "ejemplar". El rendimiento escolar de un alumno está en proporción directa a su conocimiento de la lengua. Es decir, a su capacidad de comprensión y de expresión para fijar ideas y ordenar conceptos. El método debe ser el método comunicativo funcional, creativo-productivo, dirigido a la producción discursiva en sus variantes para lograr textos coherentes. Un método que sea consecuente con todos los principios fundamentales de la sociolingüística, con los fundamentos pragmáticos que rigen la interacción comunicativa, tanto en las vertientes de oralidad como de la escrituralidad; un método gradual y participativo, en suma.

Es evidente que el profesor debe estar familiarizado no sólo con los conocimientos lingüísticos, sino también con los paralingüísticos. Pero no lo es menos que no debe enseñar a sus alumnos las teorías de todos esos estudios. Enseñar lengua no consiste solamente en enseñar gramática y análisis sintáctico o morfológico. Hay que enseñar cómo se expresan los sentimientos, los pensamientos, las dudas, los ruegos, cómo se compone todo tipo de textos, cómo se controla al interlocutor en una discusión o debate, cómo se debe hablar en público, cómo se adecua la comunicación a cada situación y circunstancia. Y, por supuesto, cómo aprender a debatir, a hablar y a argumentar, a producir breves relatos, primero y más complejos, después, a redactar informes, instancias; un currículum, un reportaje, un artículo de opinión, un editorial, una crónica, un guión de cine. El conocimiento de la lengua debe enseñar a pensar, a ordenar las opiniones y argumentos, a reflexionar sobre la vida interior de las palabras.

La enseñanza y aprendizaje de la lengua debe estar al servicio del hablante y ha de facilitarle los mecanismos formales y de contenido necesarios para comunicarse. Para ello, hay que partir de esos contenidos comunicativos y de sus intenciones. Habremos de hacer que se ejercite en la comunicación de pensamientos organizados, a través de proposiciones adecuadas y bien construidas, que hemos de explicar; habremos de enseñarlo a expresarse en cualquier situación y contexto, habremos de obligarlo a ejercitarse en proponer opiniones, respetando a los interlocutores, a escuchar y pensar las respuestas, a mostrar su asentimiento o lo contrario ante opiniones diversas, a hacer un ruego en diversos niveles y circunstancias, a saber manifestarse, con tolerancia, ante ideas contrarias, a relativizar la opinión de los demás y las suyas 
propias, a practicar las técnicas de argumentación y dialéctica, a buscar la precisión y concisión en sus enunciados y mensajes. Asimismo, habrá que mostrarle, para que lo practique, cómo se pueden expresar afectos y desafectos, emociones y disgustos, felicitaciones e increpaciones contenidas. Hay que enseñar a comunicar en un lenguaje cortés e indirecto los ruegos, los mandatos, como sugerencias, los consejos, como colaboración, las opiniones propias más sólidas, sin enfatizarlas excesivamente ni imponiéndolas; a saber hablar sin gritar, a guardar los turnos en la conversación.

Hay que enseñar a los alumnos la diversidad de los actos comunicativos, a formular actos locutivos, actos ilocutivos (las intenciones comunicativas de los hablantes), actos perlocutivos (los efectos que producen los mensajes de acuerdo con sus intenciones comunicativas).

El método, pues, debe estar orientado al desarrollo práctico de los mecanismos que sirvan para la producción de textos tanto orales como escritos. Sería útil organizar los mensajes a partir de las llamadas funciones del lenguaje, debidamente estructuradas y sistematizadas. Enseñar a comunicar como punto de partida y como punto de llegada de la concepción de la lengua como instrumento de comunicación.

La expresión del tiempo, del espacio, de la causa, de la comparación, del contraste, de la hipótesis, de la finalidad, de la aserción, de la objeción, del deseo, de la exhortación, de la duda, de la consecuencia, y el análisis de las estructuras o construcciones lingüísticas que sirven para dicha expresión, son aspectos insustituibles en una didáctica consecuente con la concepción del español como privilegiado sistema de comunicación (Peñalver 2009). Lo mismo que el análisis de las estructuras y características de las modalidades textuales por su modalidad, secuencia o actitud discursiva usada (narración, descripción, argumentación, exposición), por el ámbito (desde el texto administrativo al publicitario) y, dentro de este último apartado, por la práctica discursiva (desde la instancia al folleto). Una diversidad que debe ser rigurosamente estudiada en la oralidad y en la escrituralidad, con el objetivo de llevar a la práctica con un resultado óptimo el desarrollo de las destrezas receptivas: comprensión lectora (resumen, comprensión interpretativa, comprensión reflexiva y comentario crítico, donde ocupe un lugar esencial, la opinión personal, argumentada y razonada), de las actividades productivas (producción de textos escritos, producción de textos orales), interacción, mediación. Una síntesis, en suma, equilibrada y estrechamente relacionada de las destrezas comunicativas tanto receptivas como productivas.

Para el logro de estos fines, es necesario fortalecer nuestra competencia lingüística, de manera que la misma nos permita dominar los conocimientos (o saberes) ortográficos (en el caso de la lengua escrita), fónicos, gramaticales, semánticos y léxicos. Y todo este proceso con la finalidad de descubrir, partiendo del significado literal, el significado contextual y pragmático, la intención comunicativa, las ideas principales, el tema y lo esencial de cualquier texto sea escrito o sea oral.

\section{Conclusiones}

Enseñar a nuestros alumnos, una vez conseguida la adecuada base lingüística, psicológica y pedagógica, a describir, a narrar, a argumentar, a exponer y a producir y a construir el texto propio de cualquier ámbito profesional debe constituir el propósito del estudio de una asignatura como la de Lengua y Literatura Española en el Bachillerato. 
Para la consecución de estos objetivos, el referente esencial será el Marco Común Europeo de Referencia para las Lenguas (MCERL). Leer y escribir, escuchar, hablar y conversar, junto con la interacción y la mediación, son destrezas que, partiendo del conocimiento de la lengua (teórico y pragmático) y de la educación literaria, debemos aplicar en los diversos ámbitos: personal, público, profesional y educativo.

Como se indica en el MCERL, en el ámbito personal habrá que tener en cuenta los textos orales y escritos que conciernen a las relaciones familiares y las prácticas sociales individuales; en el ámbito público, los que conciernen a la interacción social corriente (entidades empresariales y administrativas, los servicios públicos, las actividades culturales y de ocio de carácter público, las relaciones con los medios de comunicación, asociaciones, partidos políticos); en el ámbito profesional; los relacionados con la empresa, sindicatos, compañeros de trabajo; en el ámbito educativo, los relacionados con el contexto de aprendizaje y formación: escuela, instituto, universidad, centros de formación.

El texto debe ser el fin y el referente de esta aplicación metodológica como resultado de la suma de todas las competencias (o saberes), entre las que no pueden quedar al margen la competencia psicolingüística y la competencia sociolingüística. Una competencia comunicativa, basada en una sólida competencia lingüística y literaria, en la que se integren de forma equilibrada las competencias fónica, gramatical, semántica y léxica, por un lado, y, por otro, la competencia pragmática, la sociolingüística, la psicolingüística, la paralingüística y la discursiva, favorecerá, en todas sus dimensiones, el proceso de enseñanza y aprendizaje, encaminado a la producción de textos escritos y orales en la diversidad de su manifestación.

El paso de la palabra a la oración, de la oración al párrafo y del párrafo al texto constituirá un éxito y logrará unos resultados que deben ser orientados al propio ámbito, laboral, comercial, administrativo y académico, con el fin de que el dominio del español se convierta en un medio que nos ayude a triunfar en la empresa y en cualquier trabajo. Por todo ello, hacemos nuestras, por un momento, afirmaciones tan acertadas como las de G. Rojo (1985: 11): "La lengua materna es la materia más importante de todo el currículum anterior a la Universidad, aunque solo sea por el hecho innegable de que constituye el medio por el que circulan todos los demás conocimientos".

\section{OBRAS CITADAS}

Alvar Ezquerra, M. 2003. La enseñanza del léxico y el uso del diccionario. Madrid: Arco/ Libros.

Álvarez, G. 1995. “Competencia discursiva y textual del hablante nativo”. RLA 33: 5-14.

Benot, E. 1889. Arquitectura de las lenguas. III vols. Madrid: Núñez Samper.

Cassany, D. 2006. Taller de textos. Leer, escribir y comentar en el aula. Barcelona: Graó.

Cassany, D. M. Luna y G. Sanz. 2008. Enseñar lengua. Barcelona: Graó.

Gómez Torrego, L. 2011[2000]. Ortografía de uso del español actual. Madrid: SM. 2011[1997]. Gramática didáctica del español. Madrid: SM. Gómez 2011[2006]. Hablar y escribir correctamente. Gramática normativa del español actual, II vols. Madrid: Arco/Libros. Nueva edición: 2011. 2011[2006]. Análisis sintáctico. Teoría y práctica. Madrid: SM. 2011[2008]. Análisis morfológico. Teoría y práctica. Madrid: SM. 
2011. Las normas académicas: últimos cambios. Madrid: SM.

González Nieto, L. 1981. "La renovación didáctica necesaria en la enseñanza de la lengua". Actas de I Simposio de Lengua y Literatura para profesores de Bachillerato. Madrid: Castalia. 169-181.

Lliteras, M. 2001. "Hacia la descripción del español hablado. La Arquitectura de las lenguas de Eduardo Benot". Actas del II Congreso Internacional de la Sociedad Española de Historiografía Lingüística. Madrid: Arco/Libros. 645-656.

Consejo de Europa. 2002. Marco común europeo de referencia para las lenguas: aprendizaje, enseñanza, evaluación. 2002. Trad. de Instituto Cervantes. Estrasburgo: Consejo de Europa, Ministerio de Educación y Grupo Anaya.

Medina, A. 1988. "Didáctica de la Lengua". Didáctica de la Lengua y Literatura. Madrid: Anaya.

Peñalver Castillo, M. 1991. La lingüística y la enseñanza de la lengua española en el Bachillerato. Granada: Comares.

. 1993. Estudios de historia de la lingüística española. Almería: Instituto de Estudios Almerienses.

1995. La escuela de Menéndez Pidal y la historiografía lingüística hispánica. Aproximación a su estudio. Almería: Universidad.

. 1998. Cuestiones de uso del español actual. Granada: Comares.

.2000. Edición y estudio de los Breves apuntes sobre los casos y las oraciones (1853)

de Eduardo Benot. Granada: Comares.

. 2009. "Las oraciones finales en el español hablado en América". Estudios lingüísticos del español hablado en América. Madrid: Visor Libros: 353-434.

Pilleux, M. 2001. "Competencia comunicativa y análisis del discurso". Estudios Filológicos 36: $143-152$.

Poch Olive, M. 1983. "Posibles aplicaciones de la fonética a la enseñanza de la Lengua y Literatura españolas en BUP y COU". Actas del III Simposio de Lengua y Literatura para profesores de Bachillerato. Oviedo.

Polo, J. 1972. Lingüística, investigación y enseñanza (notas y bibliografía). Madrid: Oficina de Educación Iberoamericana.

Quilis, A. 1978. "La enseñanza de la lengua materna”. Aportes de la lingüística a la enseñanza del español como lengua materna (H. López Morales, ed.). Boletín de la Academia Puertorriqueña de la Lengua: 3-29.

RAE. 1996. Diccionario escolar de la lengua española. Madrid: Espasa.

. 2001. Diccionario de la lengua española. 22 $2^{\mathrm{a}}$ edición. Madrid: Espasa Calpe.

2005. Diccionario panhispánico de dudas. Madrid: Santillana.

2005. Diccionario del estudiante. Madrid: Santillana.

2005. Diccionario del estudiante, Madrid: Santillana. Nueva edición: 2011.

2006. Diccionario esencial de la lengua española. Barcelona: Vox.

2007. Diccionario práctico del estudiante. Santillana.

2009. Nueva gramática de la lengua española. Morfología y sintaxis. I volumen. Madrid: Espasa Libros.

2009. Nueva gramática de la lengua española. Sintaxis. II volumen. Madrid: Espasa Libros.

2010. Manual de una nueva gramática de la lengua española. Madrid: Espasa Libros.

2010. Diccionario de americanismos. Santillana.

2010. Ortografía de la lengua española. Madrid: Espasa Libros.

2011. Nueva gramática básica de la lengua española. Madrid: Espasa Libros.

2011. Nueva gramática de la lengua española. Fonética y fonología. III volumen. Madrid: Espasa Libros.

Rojo, G. 1985. "Sobre los aprendizajes lingüísticos en España”. Actas del II Congreso Inter- 
nacional de Lingüística Aplicada. Valencia: Universidad: 13-21.

Santana, J. 2003. Las oraciones condicionales. Estudio en la lengua hablada. Sevilla: Universidad.

Sarmiento, R. 1991. Edición y estudio del Arte de hablar. Gramática filosófica de la lengua castellana (1910) de E. Benot. Barcelona: Anthropos.

Seco, M. 2011. Nuevo diccionario de dudas y dificultades. Madrid: Espasa Libros.

Vaquero, M. ${ }^{a}$ T. (1978). “Enseñar español, pero ¿qué español?”. Aportes de la lingüística a la enseñanza del español como lengua materna. Boletín de la Academia Puertorriqueña de la Lengua. 
